\title{
Evaluasi taman terapeutik pada Taman I Gusti Ngurah Made Agung Kota Denpasar
}

\author{
Alfin Christian Massie ${ }^{1}$, Ni Nyoman Ari Mayadewi2 ${ }^{\star}$, I Nyoman Gede Astawa²
}

1. Program Studi Arsitektur Pertamanan, Fakultas Pertanian, Universitas Udayana, JL. PB Sudirman Denpasar 80232, Indonesia

2. Program Studi Agroekoteknologi, Fakultas Pertanian, Universitas Udayana, JL. PB Sudirman Denpasar 80232, Indonesia

*E-mail: arimayadewi@unud.ac.id

\begin{abstract}
Evaluation on Therapeutic Garden in I Gusti Ngurah Made Agung Park at Denpasar City. I Gusti Ngurah Made Agung park is one of the city parks in Denpasar City that has therapeutic facilities provided to support the activities of the people of Denpasar City. Therapeutic park is an open space specifically designed to meet the physical, psychological, social, and spiritual needs of humans as users. This study aims to evaluate the characteristics and design concepts of a therapeutic garden in I Gusti Ngurah Made Agung park. Methods were used for the research are preparation, inventory, analysis, evaluation and synthesis. The results of this study indicate that the therapeutic garden in the park of I Gusti Ngurah Made Agung was still not in accordance with the design criteria according to experts. Therefore, it can be recommended that a garden design that meets the therapeutic garden criteria, includes: a) Official entrance planning; b) Redesigned pedestrian paths that comply with standards; c) Addition of softscape and hardscape with accents; d) Addition of aromatic plants; e) Addition of noise reducing plants; f) Providing pedestrian paths with a variety of textures; g) Additional facilities for security improvements; h) Even distribution of garden elements; i) Addition of local plants and ornamental plants; j) Addition of water element; k) Addition and improvement of facilities for users with special needs; l) Realignment of park space to support park activities.
\end{abstract}

Keywords: design criteria, I Gusti Ngurah Made Agung park, therapeutic park.

\section{Pendahuluan}

Wilayah perkotaan membutuhkan ruang terbuka untuk menunjang aktivitas masyarakat, menciptakan kebersihan, kesehatan, keserasian, dan keindahan wilayah kota sekaligus mengendalikan iklim mikro. Menurut Peraturan Menteri No. 1 Tahun 2007 tentang Penataan Ruang Terbuka Hijau Kawasan Perkotaan (RTHKP), terdapat 23 jenis RTHKP, salah satunya adalah taman kota. Secara spesifik taman kota juga berfungsi sebagai ruang dengan fungsi terapeutik, yaitu ruang terbuka yang didesain secara khusus untuk memenuhi kebutuhan fisik, psikologi, sosial, dan spiritual manusia sebagai penggunanya. Dalam perencaan taman perlu dilakukan pemilihan dan penataan secara detail terhadap elemen-elemen taman agar suatu taman dapat tercapai nilai fungsional dan nilai estetika (Arifin et al., 2008).

Berdasarkan fungsinya, taman terapeutik sangat memungkinkan untuk ditempatkan pada ruang terbuka hijau kawasan perkotaan. Ruang terapi pada ruang terbuka di Indonesia pada umumnya hanya terdapat jalur refleksi, akan lebih bermanfaat apabila diterapkan taman terapeutik yang sesuai dengan kriteria. Evaluasi pada taman kota yang sudah dibangun perlu dilakukan terhadap fungsi taman terapi, sehingga taman menjadi area terapi sehat milik publik. Taman terapeutik mempunyai nilai estetika dan fungsional yang spesifik dan harus diperhatikan dalam perencanaannya. Fasilitas yang ada pada taman terapeutik ini perlu dievaluasi dikarenakan perencanaan yang masih belum maksimal, seperti kurangnya tanaman aromatik yang berfungsi menstimulasi indera penciuman (Stigsdotter dan Grahn, 2002), kurangnya tanaman pereduksi kebisingan untuk meminimalisir gangguan (Marcus dan Barnes, 2008), kurangnya sarana prasarana dengan lebar dan panjang jalur yang sesuai dengan kebutuhan pengunjung agar dapat dilalui oleh semua golongan umur dan fisik pengunjung (Marcus, 2000), kurangnya penanda ciri pintu masuk yang dapat menarik dan mengajak pengunjung untuk masuk ke taman (McDowell dan McDowell, 2008).

Penelitian ini diharapkan mampu memberikan masukan berupa rekomendasi kepada pemerintah mengenai desain yang sesuai dengan kriteria, apabila hasil evaluasi menunjukkan bahwa konsep desain yang sudah ada tidak sesuai dan tidak fungsional. Rekomendasi yang dihasilkan juga diharapkan bisa menjadi acuan unutuk pembangunan taman terapeutik selanjutnya. Pengguna diharapkan dapat merasakan manfaat yang positif dari taman terapeutik di Taman I Gusti Ngurah Made Agung. 


\section{Metode}

\subsection{Lokasi dan Waktu Penelitian}

Penelitian ini berlokasi di Taman I Gusti Ngurah Made Agung, Desa Dauh Puri Kangin, Kecamatan Denpasar Barat, Kota Denpasar, Bali (Gambar 1). Penelitian ini dilakukan dari bulan April 2018 hingga Desember 2018.

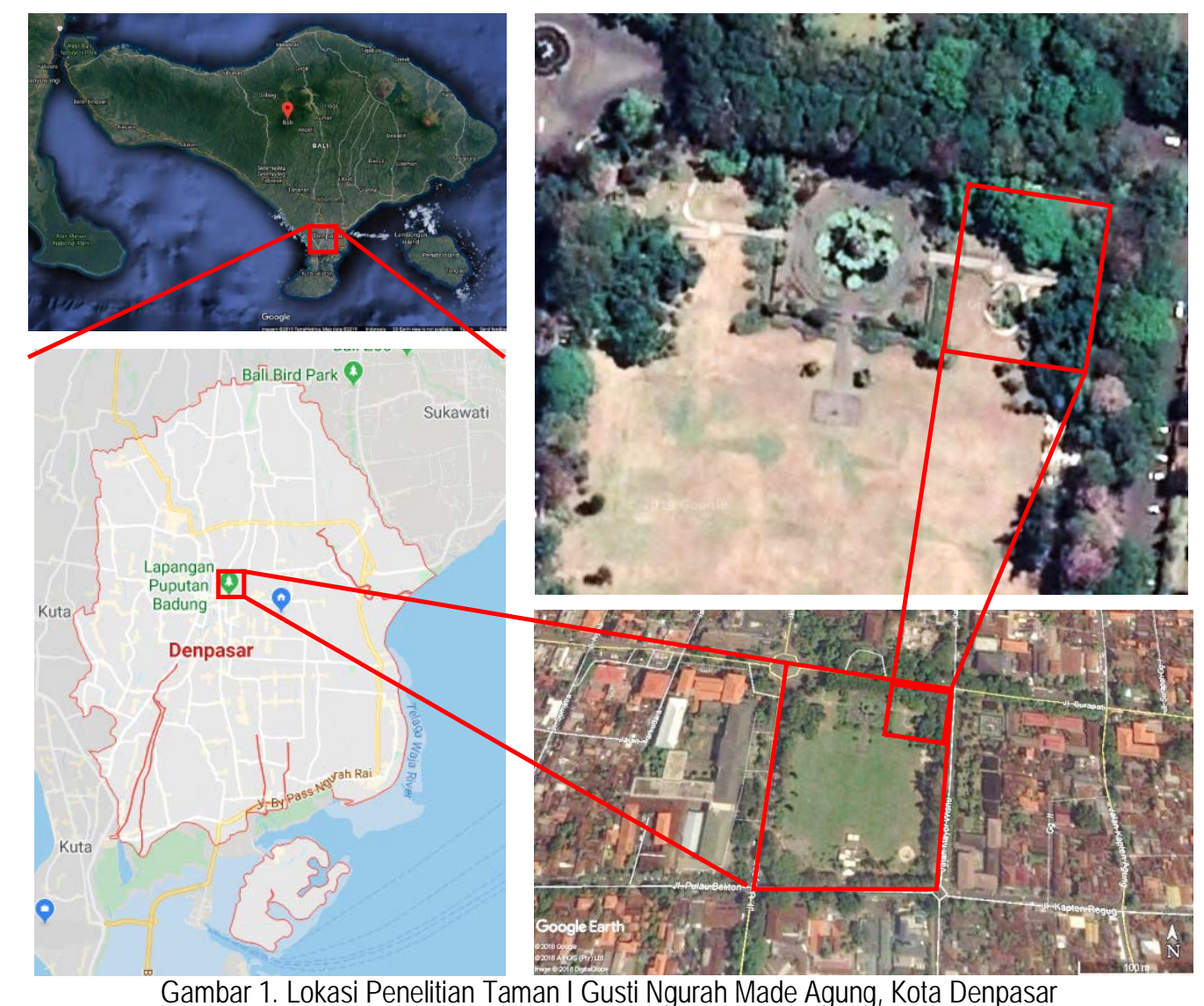

\section{$2.2 \quad$ Alat}

Alat yang digunakan dalam penelitian ini adalah kamera digital dan dibantu dengan perangkat lunak penunjang seperti Microsoft Word, Microsoft Excel, Autodesk AutoCAD, Sketch Up, Adobe Photoshop, Masterplan Taman I Gusti Ngurah Made Agung dan Taman Terapeutik pada Taman I Gusti Ngurah Made Agung.

\subsection{Metode Penelitian}

Tahapan penelitian ini berupa persiapan penelitian, inventarisasi, analisis, evaluasi, dan sintesis berupa penyusunan rekomendasi desain taman terapeutik pada Taman I Gusti Ngurah Made Agung. Pengumpulan data dilakukan dengan membagikan lembar kueisioner secara acak kepada pengguna taman terapeutik sebanyak 30 responden. Kuisioner ini menggunakan metode skala Likert, dengan cara membubuhkan tanda centang pada 5 titik respon (Likert, 1932).

Marcus dan Barnes (2008), Mc Dowell dan Mc Dowell (2008), Stiggsdotter dan Grahn (2002), Marcus (2000) merumuskan beberapa standar kriteria untuk taman terapeutik. Standar kriteria ini disusun menggunakan KPI (Key Performance Index) yang terdiri dari lima komponen berdasarkan pendapat para ahli mengenai taman terapeutik yang sesuai dengan kriteria standar. Pada lembar penilaian KPI ditentukan bagaimana kulitas dari kelima komponen tersebut menurut pengamatan yang dilakukan oleh peneliti. KPI didapatkan berdasarkan perbandingan nilai aktual (eksisting) dengan nilai standar. Nilai aktual memiliki kisaran 1 sampai 3. Nilai 1 berarti "Tidak sesuai kriteria standar", 2 berarti "Kurang sesuai kriteria standar" dan 3 berarti "Sesuai kriteria standar". Sedangkan nilai standar adalah 3. Nilai KPI terendah dari hasil perbandingan nilai aktual dan nilai standar adalah 0,33 , sedangkan nilai KPI tertinggi adalah 1 , dimana $0,33 \leq \mathrm{KPI}<0.67$ berarti belum sesuai dengan standar, dan kisaran $0,67 \geq \mathrm{KPI} \leq 1$ berarti sesuai kriteria standar (Hidayah, 2010). 


\section{Hasil dan Pembahasan \\ 3.1 Inventarisasi}

3.1.1 Aspek Fisik

Taman I Gusti Ngurah Made Agung berlokasi di Desa Dauh Puri Kangin, Kecamatan Denpasar Barat, Kota Denpasar dan taman terapeutik berada pada bagian timur laut. Taman I Gusti Ngurah Made Agung dikelilingi dengan berbagai atraksi Kota Denpasar, pada bagian barat laut terdapat patung catur muka dan titik nol Kota Denpasar, pada bagian timur terdapat Museum Bali dan Pura Jagatnatha. Sementara pada bagian barat merupakan Kodam IX / Udayana dan Kantor Walikota Denpasar, dan pada bagian selatan merupakan kawasan pertokoan dan perkantoran. Berdasarkan pengamatan, taman terapeutik yang berada pada bagian timur laut Taman I Gusti Ngurah Made Agung mempunyai luas sebesar 20 are. Taman terapeutik pada bagian utara berbatasan langsung dengan jogging track dan Jalan Surapati, sebelah timur berbatasan dengan Jalan Mayor Wisnu serta Pura Jagatnatha, sebelah barat berbatasan dengan Monumen Puputan Badung, dan sebelah selatan berbatasan dengan lapangan rumput.

Taman terapeutik pada Taman I Gusti Ngurah Made Agung memiliki fasilitas dan utilitas untuk menunjang kegiatan para pengunjung. Fasilitas yang tersedia pada taman diantaranya adalah jalur refleksi kaki, kursi dan meja, akses disabilitas (ramp), parkiran kendaraan bermotor, dan lampu penerangan. Utilitas yang terdapat pada taman meliputi sistem penerangan, drainase dan jaringan listrik.

Vegetasi yang berada pada area tapak, didominasi oleh tanaman semak rendah, dan pohon tinggi bertajuk lebar (Tabel 1). Sedangkan untuk perkerasan, terdapat jalur refleksi yang terdiri atas batu-batuan yang disusun sedemikian rupa sehinga membentuk pola tertentu. Batuan tersebut diantaranya adalah susunan batu koral, batu sikat, dan batu alam.

Tabel 1. Daftar Vegetasi Pada Taman Terapeutik

\begin{tabular}{|c|c|c|c|}
\hline \multirow[t]{2}{*}{ No. } & \multicolumn{2}{|c|}{ Nama Tanaman } & \multirow{2}{*}{ Jumlah } \\
\hline & Nama lokal & Nama Latin & \\
\hline \multicolumn{4}{|c|}{ Pohon } \\
\hline 1. & Bungur & Lagerstroemia speciosa & 1 \\
\hline 2. & Cempaka & Magnolia champaca & 4 \\
\hline 3. & Ketapang & Terminalia catappa & 1 \\
\hline 4. & Palem Kuning & Dypsis lutescens & 14 \\
\hline 5. & Tabebuia kuning & Tabebuia cassinoides & 5 \\
\hline 6. & Tabebuia pink & Tabebuia rosea & 2 \\
\hline \multicolumn{4}{|c|}{ Semak } \\
\hline 1. & Bougenvil & Bougenvillea sp. & 105 \\
\hline 2. & Cemara & Casuarinaceae sp. & 21 \\
\hline 3. & Kaki laba-laba & Osmoxylon lineare 'Yellow' & 705 \\
\hline 4. & Korimbosa & Tabernaemontana corymbosa & 996 \\
\hline 5. & Krokot hijau & Portulaca oleracea & 35 \\
\hline 6. & Pangkas kuning & Duranta sp. 'Dwaft yellow' & 470 \\
\hline 7. & Pucuk Merah & Syzygium oleina & 20 \\
\hline 8. & Roalia & Ruellia brittoniana & 122 \\
\hline 9. & Sambang colok & Aerva sanguinolenta & 150 \\
\hline 10. & Sambang darah & Excoecaria cochinchinensis & 140 \\
\hline 11. & Spider lilly & Hymenocallis speciosa & 55 \\
\hline 12. & Taiwan beauty & Cuphea hyssophifolia & 785 \\
\hline 13. & Teh-tehan & Acalypha macrophylla & 1059 \\
\hline \multicolumn{4}{|c|}{ Ground Cover } \\
\hline 1. & Rumput jepang & Cynodon dactylon & $110 m^{2}$ \\
\hline
\end{tabular}

\subsubsection{Aspek Sosial}

Kegiatan dan aktivitas yang dilakukan oleh para pengguna taman terapeutik cukup bervariasi. Menurut pengamatan yang dilakukan, pada umumnya para pengguna taman mengunjungi taman terapeutik setelah melakukan kegiatan olahraga di taman I Gusti Ngurah Made Agung. Dengan adanya perilaku pengguna yang menjadikan taman terapeutik ini sebagai tujuan akhir, hal ini menunjukkan bahwa taman ini merupakan salah satu taman yang cukup diminati.

\subsection{Analisis}

\subsubsection{Analisis Fisik}

Tidak adanya pintu masuk resmi membuat sirkulasi yang berada pada taman tersebut menjadi tidak teratur, dan menyebabkan kesemrawutan, dikarenakan pengguna akan melakukan vandalisme dengan 
memotong jalur untuk kemudahan akses menuju taman. Oleh karena itu diperlukan akses pintu masuk resmi agar sirkulasi dapat teratur. Selain itu dibutuhkan juga pagar pembatas agar tidak terjadi vandalisme oleh pengguna yang memotong langsung jalur refleksi dan merusak vegetasi yang terdapat pada taman.

Tidak adanya ciri penanda pintu masuk membuat pengguna kurang menyadari tujuan utama dari taman tersebut. McDowell dan McDowell (2008) menyatakan pintu masuk khusus yang menarik dan mengajak pengunjung ke taman merupakan salah satu elemen desain bagi taman terapeutik, karena memberikan efek fleksibilitas pada pengunjung yang hendak mengunjungi taman.

\subsubsection{Analisis Kualitas Taman}

Pada analisis kualitas taman terdiri atas kualitas visual, kualitas akustik dan kualitas aromatik. Kualitas visual yang dimaksud adalah tampilan seluruh elemen-elemen taman dan elemen-elemen lingkungan sekitar. Good view yang dihasilkan oleh elemen softscape berupa variasi bentuk dan pola tanaman (Gambar 2). Repetisi tanaman pucuk merah (Syzygium oleina) dan semak rendah taiwan beauty (Cuphea hyssophifolia) juga meningkatkan kualitas visual taman.
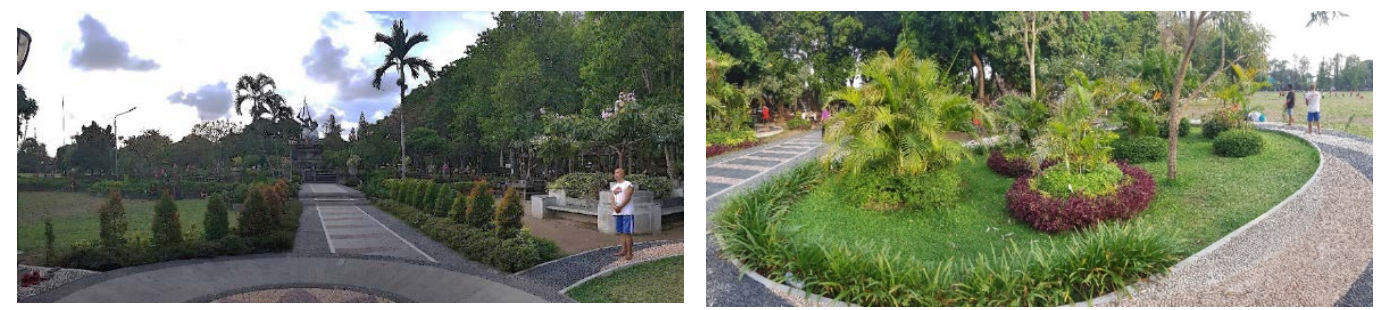

Gambar 2. Good View Pada Taman Terapeutik

Kurangnya variasi jenis tanaman dan kurang terjaganya kebersihan taman pada spot tertentu membuat kualitas visual keseluruhan taman menjadi berkurang. Untuk mengatasi hal tersebut maka diperlukan perencanaan penanaman dengan menggunakan variasi tanaman dan pola perkerasan yang mampu menghilangkan kesan gersang. Tempat sampah yang tidak terpakai dibiarkan terlihat dan penempatan yang sembarangan juga berimbas pada kualitas visual yang dihasilkan, sehingga dibutuhkan penempatan khusus dan pengalihan visual agar pandangan pengunjung tidak terganggu dengan penempatan tempat sampah yang tidak terpakai tersebut (Gambar 3).
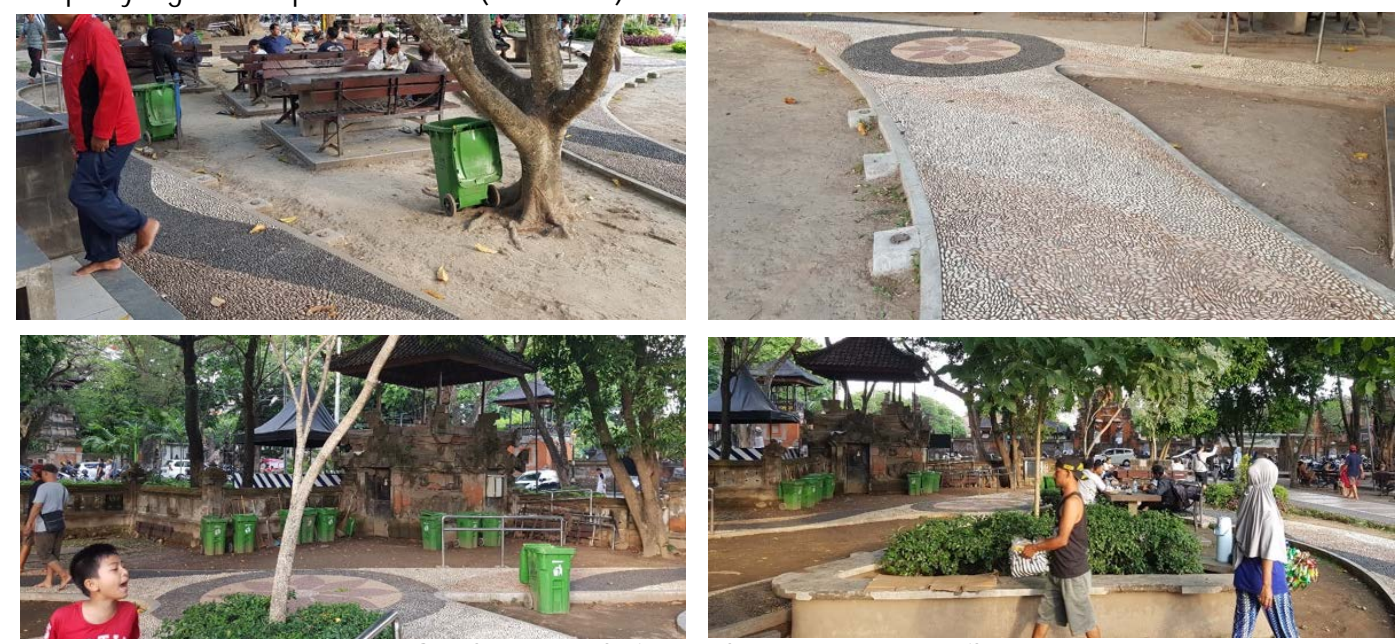

Gambar 3. Bad View Pada Taman Terapeutik

Kualitas akustik yang terdapat pada taman ini berupa suara satwa liar dan gemuruh angin. Namun kebisingan secara umum dihasilkan berupa kebisingan oleh suara kendaraan bermotor, dikarenakan taman ini berada pada sisi utara Taman I Gusti Ngurah Made Agung tepatnya bersebelahan dengan Jalan Surapati yang cukup padat. Untuk meredam suara kebisingan kendaraan bermotor, diperlukan perencanaan penanaman tanaman yang mampu meredam polusi suara dan meningkatkan kualitas akustik taman.

Berdasarkan hasil wawancara dengan pengunjung, polusi asap rokok juga menjadi kendala bagi pengunjung taman terhadap kualitas aromatik yang dihasilkan, sehingga kenyamanan pengunjung menurun. Untuk mengatasi hal tersebut dibutuhkan pengolalaan terhadap alat kebersihan taman dan perencanaan berupa penempatan papan larangan untuk merokok yang lebih terlihat. 


\subsubsection{Analisis Ruang Dalam Taman}

Ruang taman yang terdapat pada taman ini terdiri dari ruang penerimaan, ruang utama, ruang transisi, dan ruang refleksi (Gambar 4). Ruang penerimaan berada pada sisi utara, timur, dan barat taman, berfungsi sebagai pintu masuk dan keluar pengunjung. Ruang utama berfungsi sebagai tempat beraktifitas para pengunjung. Ruang transisi berada diantara ruang refleksi dan ruang penerimaan barat, ruang ini digunakan oleh pengunjung untuk peregangan sebelum memasuki ruang refleksi dan sebagai titik akses pemandangan taman. Ruang refleksi digunakan sebagai ruang pijat refleksi kaki, yang terdiri dari kombinasi bebatuan.

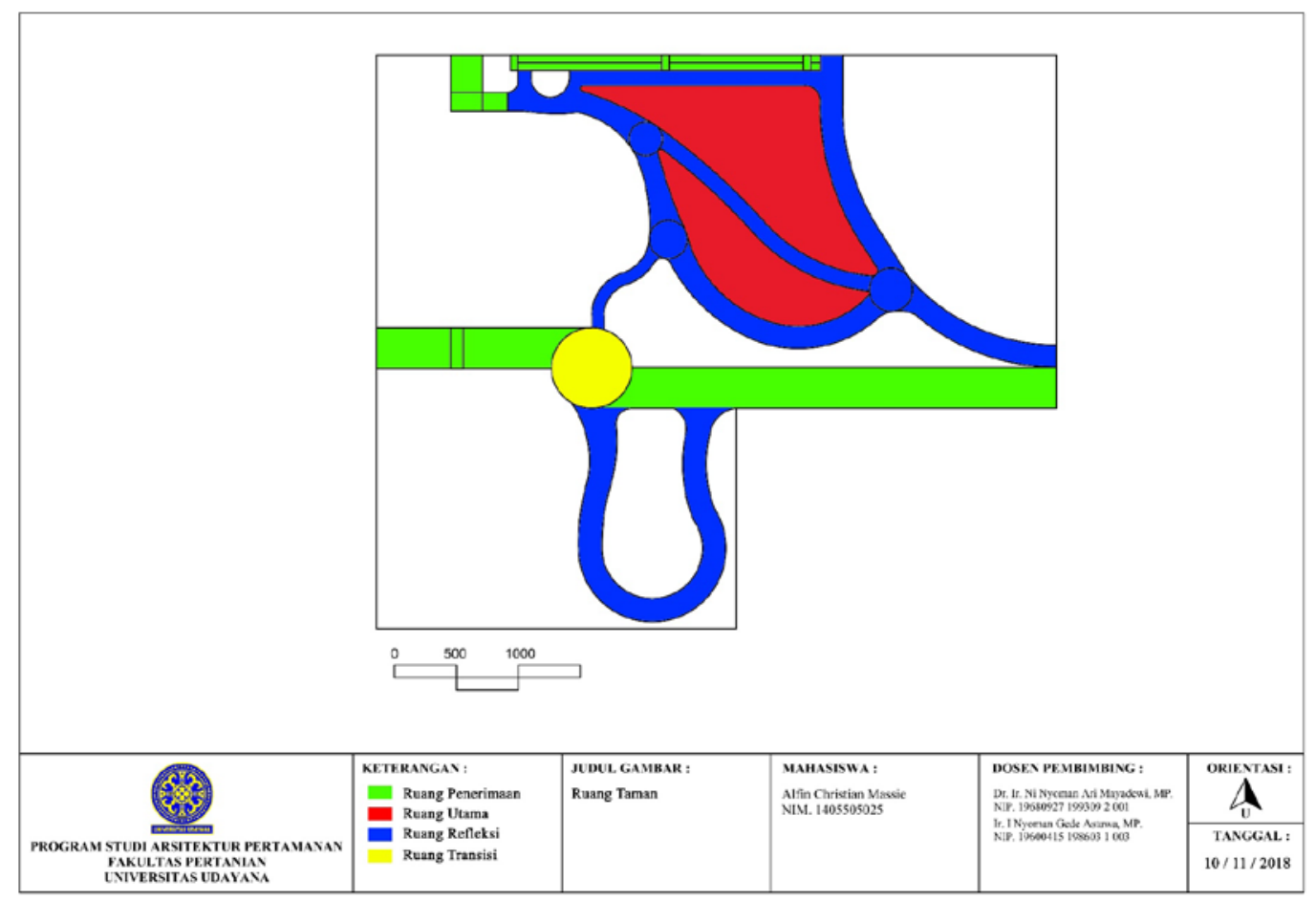

Gambar 4. Analisis Ruang Dalam Taman

Berdasarkan pengamatan, pengguna banyak memanfaatkan ruang refleksi sebagai jalan pintas menuju Taman I Gusti Ngurah Made Agung dan/atau menuju air mancur monumen puputan sehingga menghambat aktivitas ruang refleksi. Selain itu pada ruang penerimaan dimanfaatkan para pedagang yang berjualan dan pengunjung yang memanfaatkan tangga sebagai tempat duduk, sehingga mengganggu sirkulasi

\subsubsection{Analisis Elemen Taman}

Elemen tanaman didominasi oleh pepohonan yang memiliki tajuk lebar sehingga memiliki tingkat keteduhan yang tinggi, hal ini membuat tanaman penutup tanah yang tepat berada dibawah naungan pohon bertajuk lebar menjadi kering dan mati, sehingga menciptakan kesan gersang dan menurunkan kualitas visual yang dihasilkan. Kondisi elemen perkerasan terbilang cukup baik, hal ini terlihat dari kondisi kerusakan yang minim, tetapi terdapat beberapa elemen yang hilang (Tabel 2).

Tabel 2. Elemen Perkerasan Pada Taman

\begin{tabular}{clcc}
\hline No. & \multicolumn{1}{c}{ Elemen } & Kondisi & Jumlah \\
\hline 1. & Bangku Taman Kayu & Baik & 16 \\
2. & Bangku Taman Beton & Baik & 8 \\
3. & Meja Beton & Cukup Baik & 14 \\
4. & Tempat Sampah & Baik & 9 \\
5. & Handrail & Kurang Baik & 6 \\
6. & Lampu Taman & Cukup Baik & 3 \\
7. & Planter Box & Cukup Baik & 3 \\
8. & Jalur Refleksi & Baik & 1 \\
9. & Tangga & Baik & 1 \\
10. & Ramp & Baik & 1 \\
\hline
\end{tabular}

3.2.5 Analisis Sosial dan Aktivitas Pengguna Taman

Berdasarkan pengamatan yang sudah dilakukan, penggunaan taman terapeutik ramai dikunjungi saat hari libur. Pengunjung taman ini juga berasal dari berbagai macam kalangan. Seperti pada pagi hari kerja 
didominasi oleh kaum lanjut usia dan anggota TNI yang berolahraga dan peregangan otot, sore pada hari kerja didominasi oleh orang dewasa yang berdiskusi dan bermain catur. Selain itu juga terdapat kaum remaja yang memanfaatkan fasilitas bangku taman dan pedagang yang beroperasi pada sore hari. Sedangkan pada hari libur, pagi dan sore hari didominasi oleh berbagai macam kalangan, dari kaum remaja, lanjut usia, hingga keluarga yang menggunakan taman terapeutik untuk beristirahat, berdiskusi dan menggunakan jalur refleksi.

\subsection{Evaluasi}

\subsubsection{Evaluasi Fisik}

Jumlah dari perhitungan KPI yang didapatkan dari komponen fisik ini yaitu sebesar 0,67 (Tabel 3), hal ini menyatakan bahwa komponen fisik taman sesuai dengan kriteria standar.

Tabel 3. Penilaian Komponen Fisik

\begin{tabular}{lccc}
\hline \multirow{2}{*}{ Kualitas Standar } & \multicolumn{2}{c}{ Evaluasi } & \multirow{2}{*}{ KPI } \\
\cline { 2 - 3 } & $\begin{array}{c}\text { Nilai } \\
\text { Aktual }\end{array}$ & $\begin{array}{c}\text { Nilai } \\
\text { Standar }\end{array}$ & \\
\hline 1. Komponen Fisik & & & \\
Kemudahan lokasi dan akses pintu masuk & 2 & 3 & 0,67 \\
Lebar jalur jalan sesuai dengan intensitas dan fungsinya & 2 & 3 & 0,67 \\
\hline \multicolumn{1}{c}{ Jumlah } & 4 & $\mathbf{6}$ & $\mathbf{0 , 6 7}$ \\
\hline
\end{tabular}

Kemudahan lokasi dan akses pintu masuk taman memiliki nilai aktual 2, yang berarti kurang sesuai dengan kriteria standar, namun lokasi dan akses pintu masuk taman terbilang cukup mudah karena dapat dijangkau dari arah mana saja, namun kondisi ini masih belum memenuhi nilai standar dikarenakan tidak memiliki ciri penanda pintu masuk, sehingga pengunjung kurang menyadari keberadaan taman terapeutik.

Jalur yang terdapat pada taman ini berupa jalur terapi, sehingga sering terjadi kesalahan fungsi jalur terapi yang digunakan oleh pengunjung sebagai shortcut menuju taman utama. Jalur terapi memiliki lebar 120 $\mathrm{cm}$ dan $200 \mathrm{~cm}$ yang cukup apabila pengunjung saling berpapasan, namun para pengunjung yang memanfaatkan jalur terapi ini sebagai shortcut menuju taman utama menyebabkan intensitasnya menjadi padat. Dengan kondisi seperti ini, lebar dan fungsi jalur terapi memiliki nilai aktual 2 yang berarti kurang sesuai dengan kriteria standar.

\subsubsection{Evaluasi Kualitas Taman}

Hasil pengamatan terhadap komponen kualitas taman memiliki jumlah perhitungan KPI sebesar 0,54 (Tabel 4), yang menunjukkan komponen kualitas taman tidak sesuai dengan kriteria standar. Tabel 4. Penilaian Komponen Kualitas Taman

\begin{tabular}{lccc}
\hline \multicolumn{1}{c}{ Kualitas Standar } & \multicolumn{2}{c}{ Evaluasi } & \multirow{2}{*}{ KPI } \\
\cline { 2 - 3 } & Nilai Aktual & Nilai Standar & \\
2. Komponen Kualitas Taman & 2 & 3 & 0,67 \\
Penekanan kesan alami & 2 & 3 & 0,67 \\
Tidak gelap, sinar matahari cukup & 1 & 3 & 0,33 \\
Tidak monoton, perpaduan warna secara kreatif & 1 & 3 & 0,33 \\
Efek aromatik yang positif & 2 & 3 & 0,67 \\
Tidak gaduh dan terdapat suara alami & 1 & 3 & 0,33 \\
Tekstur dari material yang beragam & 1 & 3 & 0,33 \\
Memberi rasa aman, tidak membahayakan & 3 & 3 & 1,00 \\
Suhu nyaman, serta memberikan kesan keakraban dan & $\mathbf{1 3}$ & $\mathbf{2 4}$ & $\mathbf{0 , 5 4}$ \\
ketenangan & Jumlah & & \\
\hline
\end{tabular}

Penekanan kesan alami yang dihasilkan taman memiliki nilai aktual 2, dikarenakan lokasi taman yang berada pada pinggir jalan utama Kota Denpasar dan dikelilingi oleh bangunan perkantoran, namun tetap memiliki kesan alami yang dihasilkan dari pepohonan yang rimbun. Intensitas cahaya matahari yang masuk kedalam taman dapat tersaring dengan baik oleh rimbunnya pepohonan yang terdapat pada ruang taman, sehingga memiliki nilai aktual 2. Tetapi hal ini masih kurang sesuai dengan kriteria standar taman, dikarenakan terlihat beberapa tanaman mati karena ternaungi oleh pepohonan. Perpaduan warna antara beberapa elemen taman terlihat monoton, disebabkan tidak adanya paduan yang secara jelas terlihat antara elemen taman. Sehingga nilai aktual yang didapatkan yaitu 1.

Efek aromatik yang dihasilkan tidak tercium pada taman, karena tidak tersedianya tanaman aromatik pada taman, sehingga mendapatkan nilai aktual 1. Lokasi taman yang bersebelahan dengan jalan raya menghasilkan polusi suara dari kendaraan bermotor yang menganggu kenyamanan para pengunjung taman. Namun terdapat pengalihan yang positif berupa suara alami yang dihasilkan oleh angin kepada pepohonan 
pada ruang taman, dan suara satwa liar, sehingga didapatkan nilai aktual sebesar 2. Tekstur material yang terdapat pada taman masih belum beragam, sehingga mendapatkan nilai aktual 1 .

Masih terdapat beberapa fasilitas taman seperti susunan batu pada jalur terapi yang lepas dan handrail yang sudah rusak, dengan kondisi seperti ini dapat membahayakan keselamatan pengunjung. Kurangnya penerangan pada malam hari juga dapat memicu tindakan kriminal pada malam hari, hal ini dapat mengurangi rasa aman pengunjung dikarenakan tidak adanya petugas keamanan yang bertugas secara rutin. Sehingga mendapatkan nilai aktual 1.

Suhu nyaman yang dirasakan pada area taman dihasilkan dari naungan pepohonan yang rimbun, sehingga nilai aktual yang didapatkan yaitu 3. Ketenangan dan keakraban yang terdapat pada taman dihasilkan oleh rimbunnya pepohonan yang membuat suhu menjadi sejuk, namun masih terdapat gangguan dari suara yang dihasilkan oleh lingkungan sekitar taman.

\subsubsection{Evaluasi Ruang Dalam Taman}

Hasil pengamatan terhadap komponen ruang dalam taman yaitu sebesar 0,5 (Tabel 5) yang menyatakan bahwa komponen ruang dalam taman belum sesuai dengan kriteria standar.

Tabel 5. Penilaian Komponen Ruang Dalam Taman

\begin{tabular}{lccc}
\hline \multicolumn{1}{c}{ Kualitas Standar } & \multicolumn{2}{c}{ Evaluasi } & \multirow{2}{*}{ KPI } \\
\cline { 2 - 3 } & Nilai Aktual & Nilai Standar & \\
\hline 3. Komponen Ruang dalam taman & & 3 & 0,67 \\
Desain yang jelas dan tidak abstrak, tidak disorientasi & 2 & 3 & 0,33 \\
Tidak sempit, nyaman dan terdapat ruang yang beragam & 1 & $\mathbf{6}$ & $\mathbf{0 , 5}$ \\
\hline Jumlah & $\mathbf{3}$ & \\
\hline
\end{tabular}

Ruang taman yang terencana dengan baik akan memberikan kesempatan kepada pengunjung untuk mencari ruang yang dikehendaki secara bebas. Hal ini terlihat pada desain ruang taman yang tersedia pada lokasi, yaitu pengunjung dapat mengakses antar ruang yang terorientasi dengan baik tanpa ada pembatas antar ruang, sehingga menghasilkan nilai aktual 3. Namun, pengunjung yang ingin mendapatkan ruang privasi kurang terfasilitasi, dikarenakan pilihan ruang yang terbatas dan padatnya penggunaan ruang. Hal ini juga berdampak pada pergerakan fisik dan gerak tubuh menjadi terbatas.

Luasan taman yang cukup mampu memberikan kesempatan pengguna untuk mencari ruang yang dikehendaki, namun luasan taman yang tersedia masih belum optimal dan memiliki nilai aktual 1. Hal ini terjadi dikarenakan inkonsistensi lebar jalur terapi dan ada bagian jalur terapi yang terkena sinar matahari langsung tanpa adanya naungan yang membuat suhu permukaan jalur terapi menjadi panas.

\subsubsection{Evaluasi Elemen Taman}

Jumlah dari perhitungan KPI yang didapatkan dari komponen elemen taman ini yaitu sebesar 0,60 (Tabel 6), hal ini menyatakan bahwa komponen elemen taman masih belum sesuai dengan kriteria standar.

Tabel 6. Penilaian Komponen Elemen Taman

\begin{tabular}{lccc}
\hline \multicolumn{1}{c}{ Kualitas Standar } & \multicolumn{2}{c}{ Evaluasi } & \multirow{2}{*}{ KPI } \\
\cline { 2 - 3 } & Nilai Aktual & Nilai Standar & \\
4. Komponen elemen taman & 2 & 3 & 0,67 \\
Jenis tanaman lokal & 1 & 3 & 0,33 \\
Tanaman memiliki bentuk yang ornamental dan tidak abstrak & 3 & 3 & 1,00 \\
Jenis perkerasan berupa jalur jalan dan site furniture & 1 & 3 & 0,33 \\
Perkerasan memiliki bentuk yang ornamental, bertekstur, & 2 & 3 & 0,67 \\
dan tidak abstrak & $\mathbf{9}$ & $\mathbf{1 5}$ & $\mathbf{0 , 6 0}$ \\
\hline Elemen air & Jumlah & & 3
\end{tabular}

Salah satu ciri khas dari taman bergaya bali adalah pemilihan tanaman lokal bali seperti andong, puring, jepun bali, dan samblung. Pada taman terapeutik ini terdapat beberapa tanaman lokal, namun jenis yang digunakan kurang beragam, sehingga nilai aktualnya adalah 2. Bentukan dari tanaman yang tersedia masih belum terlihat ornamental, dikarenakan tanaman yang berada pada lokasi tidak terawat dan tumbuh liar sehingga menghasilkan bentuk yang abstrak, serta pola tanaman yang tersedia juga masih tidak jelas.

Jenis elemen hardscape yang terdapat pada taman memiliki nilai aktual 3, dikarenakan sudah terdapat jalur pejalan kaki berupa jalur terapi dan site furniture yang tersebar pada ruang taman. Namun pada bentukannya didominasi oleh bentuk yang monoton, susunan bebatuan yang terdapat pada jalur terapi memiliki pola yang abstrak dan memiliki tekstur yang kurang beragam. Sehingga nilai aktual yang dihasilkan dari bentukan hardscape adalah 1. Menurut Andyna (2012), Taman bergaya bali juga identik dengan elemen air, namun elemen air tersebut tidak tersedia pada taman terapeutik, melainkan berada pada luar area taman. Maka hal ini kurang sesuai dengan kriteria standar dan mendapatkan nilai aktual 1. 
3.3.5 Evaluasi Sosial dan Aktivitas Pengguna Taman

Jumlah dari perhitungan KPI yang didapatkan dari komponen sosial dan aktivitas pengguna taman ini yaitu sebesar 0,33 (Tabel 7), yang berarti masih belum sesuai dengan kriteria standar.

Tabel 7. Penilaian Komponen Sosial dan Aktivitas Pengguna Taman

\begin{tabular}{lccc}
\hline \multicolumn{1}{c}{ Kualitas Standar } & \multicolumn{2}{c}{ Evaluasi } & \multirow{2}{*}{ KPI } \\
\cline { 2 - 3 } & Nilai Aktual & Nilai Standar & \\
\hline 5. Komponen sosial dan aktivitas pengguna taman & & & \\
Dapat dilalui oleh pengunjung dengan keterbatasan fisik & 1 & 3 & 0,33 \\
Aktivitas sesuai dengan fungsi ruang dan elemen & 1 & 3 & 0,33 \\
\hline \multicolumn{1}{c}{ Jumlah } & $\mathbf{2}$ & $\mathbf{6}$ & $\mathbf{0 , 3 3}$ \\
\hline
\end{tabular}

Dengan adanya ramp di sisi utara taman dapat memudahkan pengunjung dengan keterbatasan fisik, namun handrail yang tersebar di dalam taman terapeutik berada dalam kondisi yang kurang layak, diantara handrail tersebut sudah berada dalam keadaan rusak dan hilang. Dengan kondisi demikian nilai aktual yang didapatkan yaitu 1, yang berarti tidak sesuai dengan kriteria standar.

Pengunjung yang terdapat pada taman ini sudah mencakup semua golongan dan umur. Jenis aktivitas yang terdapat pada taman ini juga sudah menunjukkan keberagaman yang dapat mendukung aktivitas aktif dan pasif. Namun terdapatnya aktivitas komersial di ruang dalam taman menimbulkan ketidaksesuaian aktivitas dengan fungsi ruang dan elemen taman, maka nilai aktual yang didapatkan yaitu 1.

\subsubsection{Evaluasi Persepsi Pengguna Terhadap Taman Terapeutik}

Pada Tabel 8 merupakan hasil dari perhitungan total skor yang didapatkan melalui pembobotan menggunakan skala likert 1 sampai dengan 5 . Index \% yang tersedia pada tabel dibawah berguna untuk mengetahui rata-rata skor yang didapatkan dari masing-masing indikator penilaian. Apabila presentase yang didapatkan masih kurang dari 60\% (baik), maka akan dilakukan evaluasi dengan memverifikasikan data dari hasil Key Performance Index (KPI) yang sudah dilakukan oleh pengamat.

Tabel 8. Rekapitulasi Pengolahan Data Kuisioner

\begin{tabular}{|c|c|c|c|c|c|c|c|c|}
\hline \multirow[b]{2}{*}{ Kualitas Standar } & \multicolumn{5}{|c|}{ Jumlah Skor } & \multirow[b]{2}{*}{$\begin{array}{l}\text { Total } \\
\text { Skor }\end{array}$} & \multirow{2}{*}{$\begin{array}{l}\text { Index } \\
\%\end{array}$} & \multirow[b]{2}{*}{ Ket. } \\
\hline & $\begin{array}{l}\text { Sangat } \\
\text { Kurang }\end{array}$ & Kurang & $\begin{array}{l}\text { Cukup } \\
\text { Baik }\end{array}$ & Baik & $\begin{array}{c}\text { Sangat } \\
\text { Baik }\end{array}$ & & & \\
\hline \multicolumn{9}{|l|}{ 1. Komponen Fisik } \\
\hline $\begin{array}{l}\text { Kemudahan akses menuju lokasi dan pintu } \\
\text { masuk }\end{array}$ & 0 & 8 & 69 & 12 & 0 & 89 & 59,3 & Cukup \\
\hline $\begin{array}{l}\text { Kondisi jalan setapak di dalam lokasi } \\
\text { 2. Komponen Kualitas Taman }\end{array}$ & 0 & 24 & 30 & 24 & 10 & 88 & 58,7 & Cukup \\
\hline Pemandangan yang berada di sekitar lokasi & 0 & 20 & 36 & 20 & 15 & 87 & 60,7 & Baik \\
\hline Intensitas (penerangan) cahaya matahari & 0 & 2 & 51 & 40 & 10 & 103 & 68,7 & Baik \\
\hline $\begin{array}{l}\text { Efek aromatik yang ditimbulkan dari } \\
\text { tanaman maupun lingkungan sekitar }\end{array}$ & 2 & 16 & 30 & 20 & 5 & 73 & 48,7 & Cukup \\
\hline $\begin{array}{l}\text { Tingkat kebisingan yang dirasakan saat } \\
\text { berada di lokasi }\end{array}$ & 3 & 8 & 54 & 20 & 0 & 85 & 56,7 & Cukup \\
\hline $\begin{array}{l}\text { Tekstur dari material yang terdapat pada } \\
\text { lokasi (paving, batu, tanaman) }\end{array}$ & 1 & 8 & 39 & 48 & 5 & 101 & 67,3 & Baik \\
\hline Tingkat kenyamanan (suhu) & 0 & 18 & 45 & 12 & 15 & 90 & 60,0 & Cukup \\
\hline $\begin{array}{l}\text { Tingkat keamanan pengunjung terhadap } \\
\text { fasilitas yang berada pada lokasi }\end{array}$ & 3 & 20 & 30 & 24 & 5 & 82 & 54,7 & Cukup \\
\hline \multicolumn{9}{|l|}{ 3. Komponen Ruang dalam Taman } \\
\hline Desain lokasi & 0 & 30 & 18 & 20 & 20 & 88 & 58,7 & Cukup \\
\hline Luasan lokasi & 0 & 10 & 12 & 84 & 0 & 106 & 70,7 & Baik \\
\hline \multicolumn{9}{|l|}{ 4. Komponen Elemen Taman } \\
\hline Elemen air (kolam, air mancur) pada lokasi & 0 & 18 & 42 & 20 & 5 & 85 & 56,7 & Cukup \\
\hline Jenis dan bentuk tanaman & 13 & 16 & 18 & 12 & 0 & 59 & 39,3 & Kurang \\
\hline $\begin{array}{l}\text { Jenis dan bentuk (pola) yang ada pada } \\
\text { lokasi (paving, batu) }\end{array}$ & 4 & 8 & 33 & 32 & 15 & 92 & 61,3 & Baik \\
\hline $\begin{array}{l}\text { Perpaduan warna pada tanaman dan } \\
\text { perkerasan }\end{array}$ & 8 & 12 & 42 & 8 & 0 & 70 & 46,7 & Cukup \\
\hline $\begin{array}{l}\text { 5. Komponen Sosial dan Aktivitas Taman } \\
\text { Fasilitas pendukung terhadap pengunjung } \\
\text { dengan keterbatasan fisik (difabel, lansia) }\end{array}$ & 0 & 4 & 39 & 52 & 10 & 105 & 70,0 & Baik \\
\hline
\end{tabular}




\subsection{Sintesis}

Hasil evaluasi taman terapeutik yang menggunakan metode KPI menyatakan bahwa taman ini masih belum memenuhi kriteria standar taman terapeutik menurut para ahli, karena hasil perhitungan KPI yang didapatkan masih dibawah nilai yang diharapkan. Sedangkan hasil kuisioner menunjukkan index \% keseluruhan sebesar 58,4\% yang berarti cukup. Tabel 9 menunujukkan apakah kualitas standar yang tersedia pada taman terapeutik membutuhkan rekomendasi atau tidak. Pemberian rekomendasi dilakukan berdasarkan hasil konfirmasi pengunjung pada kuisioner dengan verifikasi pengamatan pada KPI (Tabel 9). Tabel 9. Rekapitulasi Perhitungan Hasil KPI dan Kuisioner

\begin{tabular}{|c|c|c|c|c|}
\hline Kualitas Standar & Pengamat & Responden & $\begin{array}{c}\text { Kode } \\
\text { Evaluasi }\end{array}$ & $\begin{array}{c}\text { Kode } \\
\text { Rekomendasi }\end{array}$ \\
\hline \multicolumn{5}{|l|}{ 1. Komponen Fisik } \\
\hline Kemudahan lokasi dan akses pintu masuk & Ya & Tidak & E1 & $\mathrm{R} 1$ \\
\hline Lebar jalur jalan sesuai intensitas dan fungsinya & Ya & Tidak & E2 & R2 \\
\hline \multicolumn{5}{|l|}{ 2. Komponen Kualitas Taman } \\
\hline Penekanan kesan alami & Ya & Ya & & \\
\hline Tidak gelap, sinar matahari cukup & $\mathrm{Ya}$ & $\mathrm{Ya}$ & & \\
\hline Tidak monoton, perpaduan warna secara kreatif & Tidak & Tidak & E3 & R3 \\
\hline Menimbulkan efek aromatik yang positif & Tidak & Tidak & E4 & R4 \\
\hline Tidak gaduh dan terdapat suara alami & Ya & Tidak & E5 & R5 \\
\hline Tekstur dari material yang beragam & Tidak & $\mathrm{Ya}$ & E6 & R6 \\
\hline Memberi rasa aman, tidak membahayakan & Tidak & Tidak & E7 & $\mathrm{R} 7$ \\
\hline $\begin{array}{l}\text { Suhu nyaman, serta memberikan kesan keakraban dan } \\
\text { ketenangan }\end{array}$ & $\mathrm{Ya}$ & $\mathrm{Ya}$ & & \\
\hline \multicolumn{5}{|l|}{ 3. Komponen Ruang dalam Taman } \\
\hline Desain yang jelas dan tidak abstrak, tidak disorientasi & Ya & Tidak & E8 & $\mathrm{R} 2$ \\
\hline $\begin{array}{l}\text { Tidak sempit, nyaman dan terdapat ruang yang } \\
\text { beragam }\end{array}$ & Tidak & Ya & E9 & R8 \\
\hline \multicolumn{5}{|l|}{ 4. Komponen Elemen Taman } \\
\hline Jenis tanaman lokal & $\mathrm{Ya}$ & Tidak & E10 & R9 \\
\hline $\begin{array}{l}\text { Tanaman memiliki bentuk yang ornamental dan tidak } \\
\text { abstrak }\end{array}$ & Tidak & Tidak & E11 & R9 \\
\hline Jenis perkerasan berupa jalur jalan dan site furniture & Ya & $\mathrm{Ya}$ & & \\
\hline $\begin{array}{l}\text { Perkerasan memiliki bentuk yang ornamental, } \\
\text { bertekstur, dan tidak abstrak }\end{array}$ & Tidak & Ya & E12 & R3 \\
\hline $\begin{array}{l}\text { Elemen air } \\
\text { 5. Komponen Sosial dan Aktivitas Pengguna Taman }\end{array}$ & $\mathrm{Ya}$ & Tidak & E13 & R10 \\
\hline Dapat dilalui oleh pengunjung dengan keterbatasan fisik & Tidak & Ya & E14 & R11 \\
\hline Aktivitas sesuai dengan fungsi ruang dan elemen & Tidak & Tidak & E15 & R12 \\
\hline
\end{tabular}

Kode evaluasi akan diberikan apabila pengamat menyatakan 'Tidak' dan responden menyatakan 'Tidak', maka akan diberikan rekomendasi. Apabila pengamat menyatakan 'Ya' dan responden menyatakan 'Ya', maka tidak diberikan rekomendasi. Apabila terdapat ketidaksesuaian pernyataan antara pengamat dan responden, maka akan tetap diberikan rekomendasi agar tercapai kualitas standar yang sesuai dengan pendapat pada ahli. Keterangan yang tertera pada tabel merupakan kode evaluasi yang akan diberikan rekomendasi agar tercapai kualitas standar yang sesuai dengan pendapat pada ahli. Kode tersebut dihasilkan berdasarkan pencocokan antara hasil perhitungan KPI dengan hasil perhitungan kuesioner yang sudah dilakukan pada tahap evaluasi. Rekomendasi yang diusulkan adalah sebagai berikut.

1. $\mathrm{R} 1=$ Perencanaan pintu masuk resmi

2. $\quad$ R2 $=$ Perencanaan kembali jalur pejalan kaki yang sesuai standar

3. $\mathrm{R} 3=$ Penambahan softscape dan hardscape yang memiliki aksen

4. $\mathrm{R} 4=$ Penambahan tanaman aromatik

5. $\quad \mathrm{R} 5=$ Penambahan tanaman pereduksi kebisingan

6. $\mathrm{R} 6=$ Penyediaan jalur dengan tekstur yang beragam

7. $\mathrm{R} 7=$ Penambahan fasilitas untuk peningkatan keamanan

8. $\mathrm{R} 8=$ Pendistribusian elemen taman yang merata

9. $\mathrm{R} 9=$ Penambahan jenis tanaman lokal dan tanaman ornamental

10. $\mathrm{R} 10=$ Penambahan elemen air

11. R11 $=$ Penambahan fasilitas pengguna berkebutuhan khusus

12. $\mathrm{R} 12=$ Penataan kembali ruang taman untuk menunjang aktivitas 

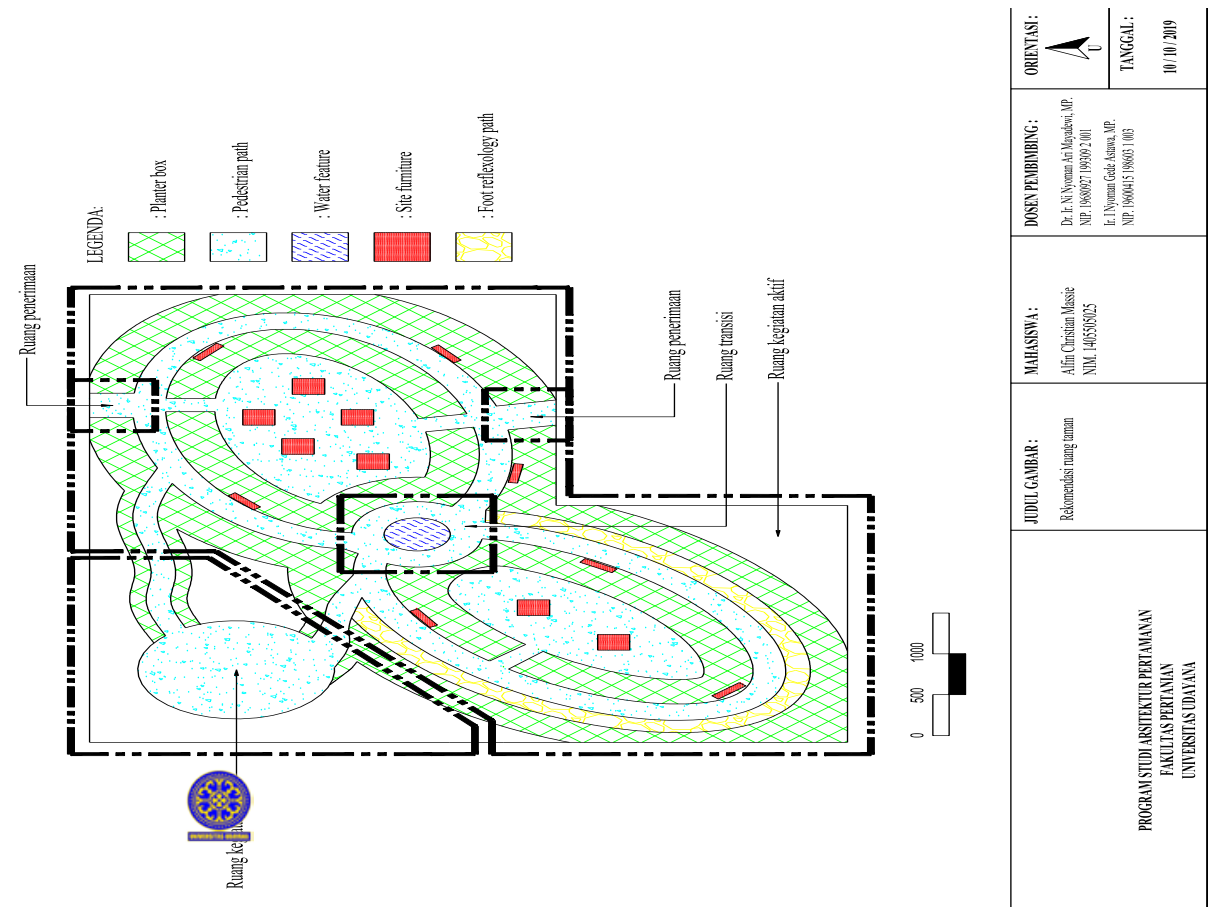

Gambar 5. Rekomendasi ruang taman

\section{Simpulan dan Saran \\ 4.1 Simpulan}

Berdasarkan hasil evaluasi menggunakan metode KPI, didapatkan bahwa karakteristik dan konsep desain taman terapeutik pada Taman I Gusti Ngurah Made Agung belum memenuhi kriteria standar menurut para ahli. Jumlah nilai aktual (eksisting) keseluruhan yang dihasilkan yaitu 31, dan jumlah nilai standar keseluruhan yang dihasilkan yaitu 57 , sehingga KPI yang dihasilkan adalah 0,54 . Sedangkan hasil evaluasi menggunakan metode kuisioner menunjukkan index \% keseluruhan sebesar $58,4 \%$ yang berarti cukup.

\subsection{Saran}

Dengan rekomendasi yang sudah diberikan berdasarkan hasil evaluasi, pengelola taman mampu mempertimbangkan rekomendasi tersebut agar taman terapeutik pada Taman I Gusti Ngurah Made Agung dapat lebih optimal dan mampu memberikan efek positif bagi pengguna taman. Peran dari pengguna taman juga sangat diharapkan agar keberlanjutan taman dapat terus terjaga. Keberlanjutan taman juga membutuhkan peran pemerintah agar dapat terus mengawasi dan bekerjasama dengan pengguna taman.

\section{Daftar Pustaka}

Andyna, A. 2012. Pesona Taman Bali. Tersedia online di: https://economy.okezone.com/read/2012/08/08 /472/674803/pesona-taman-bali (Diakses pada tanggal 2 Maret 2019).

Arifin, H. S., Munandar, A., Arifin, N.H.S., Pramukanto, Q., dan Damayanti, V.D., 2008. Sampoerna Hijau Kotaku Hijau. Jakarta: Sampoerna Hijau.

Hidayah, A.M.A. 2010. Studi Evaluasi Taman Taman Kota Sebagai Taman Terapeutik (Studi Kasus: Taman Cilaki Atas, Kota Bandung). S.P. Skripsi (Dipublikasikan) Institut Pertanian Bogor.

Kania, R. 2010. Evaluasi Taman Rumah Sakit Sebagai Healing Garden (Studi Kasus: Santosa Bandung International Hospital). S.P. Skripsi (Dipublikasikan) Institut Pertanian Bogor.

Likert, R. 1932. A Technique for the Measurements of Attitudes. Ph.D. Disertasi (Dipublikasikan) Columbia University.

McDowell, C. F., dan McDowell, T. C. 2008. The Sanctuary Garden. Di dalam: Kreitzer, M. J. Healing by Design: Healing Garden and Therapeutic Landscapes.

Marcus, C. C., dan Barnes, M. 2008. Healing Gardens: Therapeutic Benefits and Design Recommendations. Di dalam: Kreitzer MJ. Healing by Design: Healing Garden and Therapeutic Landscapes.

Marcus, C. C. 2000. Garden and Health. International Academy for Design and Health. Hal: 61-69.

Menteri Dalam Negeri. 2007. Peraturan Menteri Dalam Negeri Nomor 1 tahun 2007 tentang Penataan Ruang Terbuka Hijau Kawasan Perkotaan. Jakarta

Stigsdotter, U. A., dan Grahn, P. 2002. What Makes a Garden a Healing Garden. Journal of Therapeutic Horticulture. 13p:60-69. 